\title{
УДК: 7.046.1
}

ББК: 85.14

A43

DOI:10.18688/aa166-5-48

О. Г. Maxo

\section{Образы Муз в живописи Ренессанса и Нового времени. От студиоло Лионелло д'Эсте до картин неоклассицизма}

Образы Муз ассоциируются у любого из нас с персонажами античной мифологии. Дочери Зевса и богини памяти Мнемосины или богини согласия Гармонии покровительствовали искусствам и наукам.

В изобразительном искусстве Ренессанса они впервые появляются в середине XV столетия в серии, заказанной в 1447 г. для студиоло Лионелло д’Эсте в его палаццо Бельфьоре недалеко от Феррары [13]. Часть изображений была выполнена при жизни заказчика, а другая - уже после его кончины, при Борсо д’Эсте, который довел до конца начинание брата. К сожалению, дворец сгорел в 1632 г., а картины, созданные Анджело Макканьино, Микеле Паннонио, Козимо Турой и другими художниками, оказались рассеянными по разным коллекциям (Илл. 133). Насыщенная, но не очень ясно читающаяся аллегорическая программа заставляла на протяжении долгого времени давать различные и неточные интерпретации некоторых из этих композиций. Однако цикл выполнялся по программе, составленной Гуарино да Верона - воспитателем феррарского маркиза. Он дал описание того, как, по его мнению, должна выглядеть каждая из девяти Муз, а кроме того, предложил афористические надписи, которые должны были сопровождать их изображения [13, vol. 1, p. 324]. Совершенно очевидно, что в этом, первом изображении Муз Нового времени нет сложившейся иконографии. Более того, всячески восхваляя своего венценосного воспитанника за блестящий выбор темы для оформления его студиоло, Гуарино вкладывал в образы несколько содержательных пластов. В его интерпретации Музы покровительствуют не только поэзии, музыке или танцу, но также астрологии и истории: согласно программе Гуарино, которая не всегда точно соблюдалась художниками, Эрато, например, является покровительницей истинной любви и брачных уз. Однако описанных гуманистом мальчика и девочки, обменивающихся кольцами, рядом с нею в изображении не оказалось. Две Музы были связаны, согласно программе цикла, с сельскохозяйственными работами: Талия мыслилась как покровительница посадки растений, а Полигимния - пахоты. Такая интерпретация, скорее всего, опиралась на средневековый комментарий к «Трудам и дням» Гесиода [13, vol. 1, p. 324]. Подобная связь, вероятно, может косвенно напомнить о календарных циклах, которые были типичны для скульптурного убранства готических соборов или средневековой книжной миниатюры. 
Любопытно, что именно эти композиции с художественной точки зрения относятся к числу интереснейших в студиоло дворца Бельфьоре. Можно говорить не только об аллегорической наполненности, но и о декоративной насыщенности, даже некоторой перегруженности «Талии» работы Микеле Паннонио (Музей изобразительных искусств, Будапешт). «Полигимния» же, автора изображения которой сегодня не представляется возможным назвать (Картинная галерея, Берлин), отличается исключительной величавостью и лаконизмом монументального образа. Манера ее исполнения напоминает о стиле Пьеро делла Франческа и заставляла прежде связывать ее с рукой Франческо Коссы. Почти каждая из Муз студиоло Лионелло получила выразительную и крайне индивидуальную образную характеристику, что связано вовсе не только с тем, что они были представлены по отдельности, каждая на своей доске, и разными художниками.

Вслед за феррарским циклом и под определенным его влиянием в середине XV в. возникла серия рельефов для капеллы Муз в Темпио Малатестиано в Римини [2; 6], а немного позже появилась и живописная серия, выполненная Джованни Санти и Тимотео Вити для урбинского палаццо Дукале [17]. Она должна была располагаться в святилище Муз - маленьком помещении, связанном со студиоло Федерико да Монтефельтро. Сегодня эти изображения хранятся во Флоренции, в коллекции палаццо Корсини. Впрочем, хотя в Урбино, как и в палаццо Бельфьоре, каждая из Муз была представлена отдельно и написаны они были двумя разными художниками, образы визуально гораздо более сближены между собой, чем феррарские.

Несколько позже, в самом конце XV столетия, в 1497 г., для студиоло Изабеллы д’Эсте, до 1519 г. располагавшегося непосредственно в резиденции мантуанских маркизов замке Сан Джорджо Андреа Мантенья выполнил композицию «Парнас» (Лувр, Париж) [7]. Хоровод Муз включен в ней в сложную аллегорически-повествовательную композицию, призванную воспеть достоинства маркизы. Венчают ее Марс и Венера, воплощающие союз Франческо Гонзага и Изабеллы, союз силы и воинского благородства с красотой, любовью и процветанием. Под скалой, на которой они стоят, значительное, едва ли не центральное место в композиции отведено Музам, олицетворяющим расцвет искусств и наук в Мантуанском государстве. Ведущие хоровод под звуки кифары Аполлона, они лишены каких бы то ни было атрибутов, отчего не опознаются персонально. Однако здесь рождается новый образ - образ сообщества Муз как воплощения самой идеи гармонии, которая возникает в их соединении и слаженном движении.

Близкая по характеру интерпретация темы Муз находит свое развитие во фреске «Парнас» Рафаэля для Станцы делла Сеньятура Ватиканского дворца, выполненной в 1510-1511 гг. [8; 3] (Илл. 134). Как известно, ее основной идеей является апофеоз поэзии. В центре представлен Аполлон, играющий на лире да браччо в окружении Муз. Неслучайно считается, что ближе других к нему помещены покровительницы эпической и лирической поэзии Каллиопа и Эрато, хотя группа Муз представляется цельной, практически единой, образ той или иной героини не получает специфической характеристики. Аполлон и девять Муз расположились на вершине Парнаса, а по склонам его спускаются восемнадцать поэтов, древних и современных, вплоть до поэтов будущего, которых видят в двух фигурах справа внизу. Рафаэль с его исключительным мастерством создания гармонической композиции, величественных и одухотворен- 
ных образов не просто задает направление дальнейшего развития темы, но рождает парадигму абсолютной гармонии. Действительно, в подавляющем большинстве случаев, обращаясь к интересующей нас теме, можно заметить, что художники будут разрабатывать коллизию «Творец и Муза» или же практически давать вариации на тему «Парнаса» Рафаэля.

Несомненно, сама фреска Станцы делла Сеньятура была широко известна, но еще значительнее оказалась роль гравюры, сделалвшей композицию Рафаэля общедоступной. Известен лист Маркантонио Раймонди, который представлял первый вариант композиции, отличающийся некоторыми деталями от окончательного. Его описывал Джорджо Вазари, упоминая, что «он написал на вершине и склонах горы тенистую рощу лавровых деревьев, в зелени которых как бы чувствуется трепетание листьев, колеблемых под нежнейшим дуновением ветерков, в воздухе же - бесконечное множество обнаженных амуров, с прелестнейшим выражением на лицах, срывают лавровые ветви, заплетая их в венки, разбрасываемые ими по всему холму, где все овеяно поистине божественным дыханием» [1, с. 214]. Естественно, что подобная тема развивалась преимущественно художниками классицистически-академического направления.

В живописи XVII столетия это развитие происходит весьма интенсивно, и наиболее важное место здесь, несомненно, принадлежит произведениям Никола Пуссена. Среди наиболее значительных его работ программного характера рубежа 1620-1630-х гг. с интересующей нас темой связаны «Вдохновение поэта» и «Парнас». Тему «Вдохновение поэта» Пуссен интерпретировал дважды. В более ранней версии 1627 г. (Ганновер, Картинная галерея), которую неслучайно именовали «Вдохновение Анакреона» или «Вдохновение лирического поэта», композиция несколько более динамична. Коленопреклоненный поэт припадает к чаше, подаваемой Аполлоном, за спиной которого видна женская фигура, очевидно, Муза, а судя по атрибуту, скорее всего, - муза лирической поэзии Эрато. Второй, чуть более поздний вариант (1629-1630), хранящийся ныне в Лувре (Париж), стал признанным шедевром мастера. Гармоничная композиция предельно строга и лишь слегка оживлена жестами персонажей. Сами они также предельно идеализированы и абстрактны, воплощая идеальное совершенство. Аполлон направляет руку поэта, в котором иногда видят Вергилия, а по другую сторону от него стоит Муза. Иногда приводятся основания считать ее Эвтерпой, но выбор Пуссеном книг - «Одиссеи», «Илиады» и «Энеиды», - а также сдержанная строгость и величие ее так значительны, что точнее назвать ее Каллиопой [4, с. 98-100].

В картине «Парнас» (1630-1631, Мадрид, Прадо) Пуссен вступает в прямой диалог с Рафаэлем, а с точки зрения программы - и с итальянской аллегорической литературой [4, с. 100-102] (Илл. 135). При этом порхающие среди деревьев путти весьма определенно отсылают нас к гравюре Маркантонио Раймонди (они присутствовали и в обеих версиях «Вдохновения поэта»). Пуссен делает свою композицию более компактной, чем во фреске Станцы делла Сеньятура, наделяя ее не столько пирамидальной, сколько скорее круговой структурой, в которой фигуры персонажей расположены более тесно. Как и у Рафаэля, Музы Пуссена имеют свои атрибуты, но воспринимаются в еще большей мере единой группой, из которой почти не вычленяются отдельные персонажи. При визуальном прочтении картины центральным из них воспринимает- 
ся нимфа Касталия. Выделяясь своим светлым силуэтом, она объединяет вокруг себя всех прочих персонажей.

Но если у Пуссена Музы присутствуют в композициях с серьезной аллегорической программой, то немногим позже, в середине XVII столетия, например, в работах Эсташа Лесюера, прозванного в свое время «французским Рафаэлем», они становятся мотивом скорее декоративной живописи. В его серии панно для так называемого кабинета Муз отеля Ламбера де Ториньи (1652-1655, Париж, Лувр) фигуры собраны в компактные, почти театральные мизансцены, облачены в одежды спокойных и гармоничных тонов, их позы и жесты наделены изяществом [12].

B XVII в. образ Музы присутствует и в портретной живописи, сопровождая изображения художников, поэтов, актеров, становясь знаком их призвания. В этом качестве его можно встретить от «Автопортрета» Пуссена (1650, Париж, Лувр) [4, с. 190-192] до «Портрета А. С. Пушкина» Ореста Кипренского (1827, Государственная Третьяковская галерея, Москва) [5, с. 25-28]. Впрочем, Музы в таких композициях, даже при наличии атрибутов, превращаются в почти нейтральный символ вдохновения. Однако взаимодействие может иногда быть и гораздо более активным, как в «Портрете Гаррика между музами Трагедии и Комедии» Джошуа Рейнолдса (1761-1762, частное собрание), где актер представлен в противоречивой ситуации выбора, подобной весьма популярной аллегории «Геркулес на распутье между Добродетелью и Пороком».

В английском, да и не только английском, портрете XVIII в. неоднократно используется изображение некоторых персонажей в виде Муз. Весьма известен портрет Сары Сиддонс в виде музы трагедии кисти Дж. Рейнолдса (ок. 1784, Галерея Хантингтон, Сан-Марино). Но в контексте нашего разговора можно вспомнить композицию «Музы Британии» гораздо менее значительного мастера, Ричарда Самуэля (1779, Национальная портретная галерея, Лондон) [9]. Художник собрал в своей аллегорической картине портретные изображения девяти выдающихся женщин, проявивших себя в различных сферах. Они предстают в виде Муз в храме Аполлона, но Музы здесь поняты уже независимо от античной мифологии. Достаточно обратить внимание на Анжелику Кауфман, которая олицетворяет живопись, как известно, отсутствующую среди тех искусств, которым покровительствовали дочери Гармонии.

В мифологической живописи XVIII в. Музы все больше теряют свою индивидуальную выразительность, хотя ничуть не утрачивают популярности. В композиции только что упомянутой Анжелики Кауфман «Аполлон и Музы» они приобретают сентиментальную нежность и несколько театральную повествовательность. У Антона Рафаэля Менгса («Парнас», 1750-1760, Государственный Эрмитаж, Санкт-Петербург) их изображения наделены на первый взгляд некоторым разнообразием поз и жестов, но при этом каждая фигура представляет собой вариацию на одну и ту же тему, что соединяет их воедино. Картина Менгса пользовалась исключительным успехом и оказала сильнейшее влияние на его младших коллег, сторонников классицистической линии в живописи. Это очевидно, например, у Андреа Аппиани [18], чей «Парнас» (1811, Музей современного искусства, Милан) очень близок к композиции Менгса, и даже позже, у связанного с кругом художников-назарейцев Генриха Марии фон Гесса [14]. В его «Парнасе» (1826, Новая пинакотека, Мюнхен), выполненном для принца Карла Бавар- 
ского, персонажи становятся еще более условными. Их фигуры обрисованы весьма жестким силуэтом, одежды отличаются пестрой яркостью. В результате кажется, что, призванные декларировать мир идеальной гармонии, они делают это уже настолько умозрительно, что в органичность такой гармонии весьма сложно верить.

Конечно, выстроенный ряд можно назвать несколько тенденциозным. Многое осталось вне поля нашего зрения. Следует отметить, что в живописи северных мастеров во второй половине XVI столетия сложился тип композиции, где Музы связаны с Минервой, то есть в большей мере подчеркнуто рациональное начало. Это картины Франса Флориса («Афина и Музы») [11], Хендрика ван Балена («Минерва и Музы», 1603, частное собрание), Ханса Роттенхаммера («Минерва и Музы», 1603, Германский национальный музей, Нюрнберг). Несколько особняком стоит и знаменитая «Аллегория» Яна Вермеера (1665-1667, Вена, Музей истории искусств), связанная с темой «Художник и Муза» [10]. Но в целом они вписываются в общую тенденцию.

Подводя итог сделанных кратких наблюдений, можно отметить, что в живописи раннего Ренессанса образы Муз в соответствии с особенностями программы заказа нередко соединяли в себе элементы классического античного содержания с дополнительными средневековыми элементами. Во второй половине XV столетия иногда они могли приобретать не только аллегорико-дидактическую окраску, но и политическое звучание. Однако этот период был весьма кратким. Стремительно эволюционируя, как программное, так и изобразительное развитие темы достигает своей вершины во фреске Рафаэля «Парнас» для Станцы делла Сеньятура Ватиканского дворца. В дальнейшем, в живописи Нового времени образы Муз продолжают развиваться под несомненным ренессансным влиянием. Однако в сравнении с программной насыщенностью, характерной для эпохи Возрождения, они постепенно теряют свою индивидуальность и полисемантичность, становясь более однозначными.

\section{Литература}

1. Вазари Дж. Жизнеописания наиболее знаменитых живописцев, ваятелей и зодчих. - М.: Терра, 1994. - 214 c.

2. Венедиктов А. И. Ренессанс в Римини. - М.: Изобразительное искусство, 1970. - 132 с.

3. Гращенков В. Н. Рафаэль. - М.: Искусство, 1975. - 212 с.

4. Золотов Ю. А. Пуссен. - М.: Искусство, 1988. - 175 с.

5. Либрович С. Ф. Пушкин в портретах: История изображения поэта в живописи, скульптуре и гравюрах. - СПб.: Типография М. М. Стасюлевича, 1890. - 274 с.

6. Смирнова И. А. Искусство Италии конца XIII-XV в. - М.: Искусство, 1987. - 144 с.

7. Ferino-Pagden S. "La prima donna del mondo" Isabella d'Este. Fürstin und Mezenatin der Renaissance. - Wien: Kunsthistorisches Museum Wien, 1994. - 446 S.

8. Gombrich E. H. Raphael's Stanza della Segnatura and the Nature of its Symbolism // Symbolic Images. Studies in the art of the Renaissance II. - Oxford: Phaidon, 1978 (1972). - P. 85-101.

9. Ingamells J. National Portrait Gallery: Mid-Georgian Portraits 1760-1790. — London: National Portrait Gallery, 2004. - 588 p.

10. Kunsthistorisches Museum. Vermeer. Die Malkunst. URL: http://www.khm.at/de/besuchen/ ausstellungen/2010/vermeer-die-malkunst/ (дата обращения: 13.01.2016).

11. Luijten G. Frans Floris // The New Hollstein Dutch \& Flemish Etchings, Engravings and Woodcuts, 1450-1700. - Oudekerk aan den Ijssel: Sound \& Vision, 2011. - Vol. 21. - 123 p.

12. Mérot A. Eustache Le Sueur. 1616-1655. - Paris: Arthena, 2000. - 490 p. 
13. Le Muse e il principe: arte di corte nel Rinascimento padano: in 2 vols. / A cura di A. Di Lorenzo et al.Modena: F. C. Panini, 1991. - 391 p.; 516 p.

14. Pecht F. Heß, Heinrich von // Allgemeine Deutsche Biographie (ADB). - Leipzig: Duncker \& Humblot, 1880. - Bd 12. - S. 278-281.

15. Steppich C. J. Numine afflatur: Die Inspiration des Dichters im Denken der Renaissance. - Wiesbaden: Harrassowitz, - 2002. - $435 \mathrm{p}$.

16. Seymour Ch. Sculpture in Italy. 1400 to 1500. - Baltimore: Penguin, 1968. - 602 p.

17. Varese R. Giovanni Santi. - Fiesole: Nardini, 1994. - 274 p.

18. Zanchi A. Andrea Appiani. - Bologna: CLUEB, 1995. - 238 p.

Название статьи. Образы Муз в живописи Ренессанса и Нового времени. От студиоло Лионелло д’Эсте до картин неоклассицизма.

Сведения об авторе. Махо Ольга Георгиевна - кандидат искусствоведения, заведующая Научнометодическим сектором Научно-просветительного отдела. Государственный Эрмитаж, Дворцовая набережная, д. 34, Санкт-Петербург, Российская Федерация, 190001. omakho@mail.ru

Аннотация. Образы Муз появляются в искусстве Ренессанса в середине XV столетия, очевидно, как одно из свидетельств взаимодействия культуры Возрождения с античной культурой. Эти образы присутствуют в таких значительных ансамблях, как циклы живописных композиций для студиоло Лионелло д’Эсте во дворце Бельфьоре или связанного со студиоло Федерико да Монтефельтро в урбинском палаццо Дукале маленького святилища Муз. В произведениях мастеров Кватроченто они наполняются многогранным аллегорическим смыслом, сопрягающим античную составляющую со средневековой.

В самом конце XV столетия на смену сериям отдельных изображений приходит многофигурная композиция с многогранно разработанной программой - таков «Парнас» Андреа Мантеньи для студиоло Изабеллы д’Эте в Мантуе. Можно сказать, что своей вершины развитие темы достигает во фреске Рафаэля «Парнас» для Станцы делла Сеньятура Ватиканского дворца, где рождается парадигма абсолютной гармонии. В живописи классицизма XVII в., например в произведениях Никола Пуссена, и неоклассицизма XVIII столетия, у Антона Рафаэля Менгса, образы Муз продолжают развиваться под несомненным ренессансным влиянием. Однако в сравнении с программной насыщенностью, характерной для эпохи Возрождения, они постепенно теряют свою индивидуальность и многозначность.

Ключевые слова: музы; живопись Возрождения; студиоло; Андреа Мантенья; Рафаэль; классицизм; Никола Пуссен; Ричард Самуэль; Антон Рафаэль Менгс; Генрих Мария фон Гесс.

Title. Muses in Renaissance and Post-Renaissance Painting: From Lionello d'Este's Studiolo to Neo-Classical Paintings.

Author. Makho, Olga Georgievna - Ph. D., head of Research and Methodological Sector of the Educational Department. The State Hermitage Museum, Dvortsovaia nab., 34, 199000 St. Petersburg, Russian Federation.omakho@mail.ru

Abstract. Muses appear to be pictured in art of the Renaissance from the mid- $15^{\text {th }}$ century, possibly as one of the evidences to prove the relations between the Renaissance and classical antiquity. Their images are found in significant ensembles like the painted compositions from the Lionello d'Este's studiolo at the Belfiore palace or a small Muse sanctuary connected with Federico da Montefeltro's studiolo at Palazzo Ducale di Urbino. In these works created by the artists of Quattrocento, the images of muses are filled with versatile allegoric sense that mates classical and medieval epochs. At the end of the $15^{\text {th }}$ century, the series of separate images started to transform into multi-figured compositions with a diversified program. For example, Parnassus by Andrea Mantegna painted for Isabella d'Este's studiolo at Mantua. It seems true that the apogee of this theme was reached in Raphael's Parnassus, the fresco painted for Stanza della Segnatura at the Vatican palace, where a paradigm of absolute harmony manifests itself. With the evident influence of the Renaissance, the images of muses came into Classicism of the $17^{\text {th }}$ century (Nicolas Poussin) and Neo-classical art of the $18^{\text {th }}$ century (Anton Raphael Mengs). However, in comparison with the programme intensity of the Renaissance, these images gradually lost their individuality and polysemantic meaning.

Keywords: muses; picture of Renaissance; studiolo; Andrea Mantegna; Raffaello; classicism; Nicolas Poussin; Richard Samuel; Anton Raphael Mengs; Heinrich Maria fon Heß. 


\section{References}

Bellosi L.; Rossi A. (eds.) Vasari G. Le vite de' più eccelenti architetti, pittori et scultori italiani, da Cimabue insino a' tempi nostril. Nell'edizione per i tipi di Lorenzo Torrentino. Firenze, 1550. Torino, Einaudi Publ., 1986. Available at: http://www.letteraturaitaliana.net/pdf/Volume_5/t129.pdf (accessed 2 April 2016) (in Italian).

Di Lorenzo A. etc. (eds.) Le Muse e il principe: arte di corte nel Rinascimento padano, 2 vols. Modena, F. C. Panini Publ., 1991.391 p.; 516 p. (in Italian).

Ferino-Pagden S. "La prima donna del mondo" Isabella d'Este. Fürstin und Mezenatin der Renaissance. Wien, Kunsthistorisches Museum Wien Publ., 1994. 446 p. (in German).

Gombrich E. H. Raphael's Stanza della Segnatura and the Nature of its Symbolism. Symbolic Images. Studies in the Art of the Renaissance II. Oxford, Phaidon Publ., 1978 (1972), pp. 85-101.

Graschenkov V. N. Rafael (Raphael). Moscow, Iskusstvo Publ., 1975. 212 p. (in Russian).

Ingamells J. National Portrait Gallery: Mid-Georgian Portraits 1760-1790. London, National Portrait Gallery Publ., 2004. 588 p.

Librovich S. F. Pushkin v portretakh: Istoriia izobrazheniia poeta v zhivopisi, skulpture i gravyurah (Pushkin in portraits. History of the Poet's Image in Painting, Sculpture and Engraving). Saint-Petersburg, tipografiya M. M. Stasyulevicha Publ., 1890. 274 p. (in Russian).

Luijten G. Frans Floris. The New Hollstein Dutch \& Flemish Etchings, Engravings and Woodcuts, 14501700, vol. 21. Oudekerk aan den Ijssel, Sound \& Vision Publ., 2011. 123 p.

Mérot A. Eustache Le Sueur. 1616-1655. Paris, Arthena Publ., 2000. 490 p. (in French).

Pecht F. Heß, Heinrich von. Allgemeine Deutsche Biographie (ADB), vol. 12. Leipzig, Duncker \& Humblot Publ., 1880, pp. 278-281 (in German).

Steppich C. J. Numine afflatur: Die Inspiration des Dichters im Denken der Renaissance. Wiesbaden, Harrassowitz Publ., 2002. 435 p. (in German).

Seymour Ch. Sculpture in Italy. 1400 to 1500. Baltimore, Penguin Publ., 1968. 602 p.

Smirnova I. A. Iskusstvo Italii kontsa XIII-XV vv. (The Italian Art of the End of the $13^{\text {th }}$ to the $15^{\text {th }}$ Century). Moscow, Iskusstvo Publ., 1987. 144 p. (in Russian).

Varese R. Giovanni Santi. Fiesole, Nardini Publ., 1994. 274 p. (in Italian).

Venediktov A. I. Renessans v Rimini (The Renaissance in Rimini). Moscow, Izobrazitelnoe iskusstvo Publ., 1970. 132 p. (in Russian).

Zanchi A. Andrea Appiani. Bologna, CLUEB Publ., 1995. 238 p. (in Italian).

Zolotov Yu. A. Pussen (Poussin). Moscow, Iskusstvo Publ., 1988. 175 p. (in Russian). 


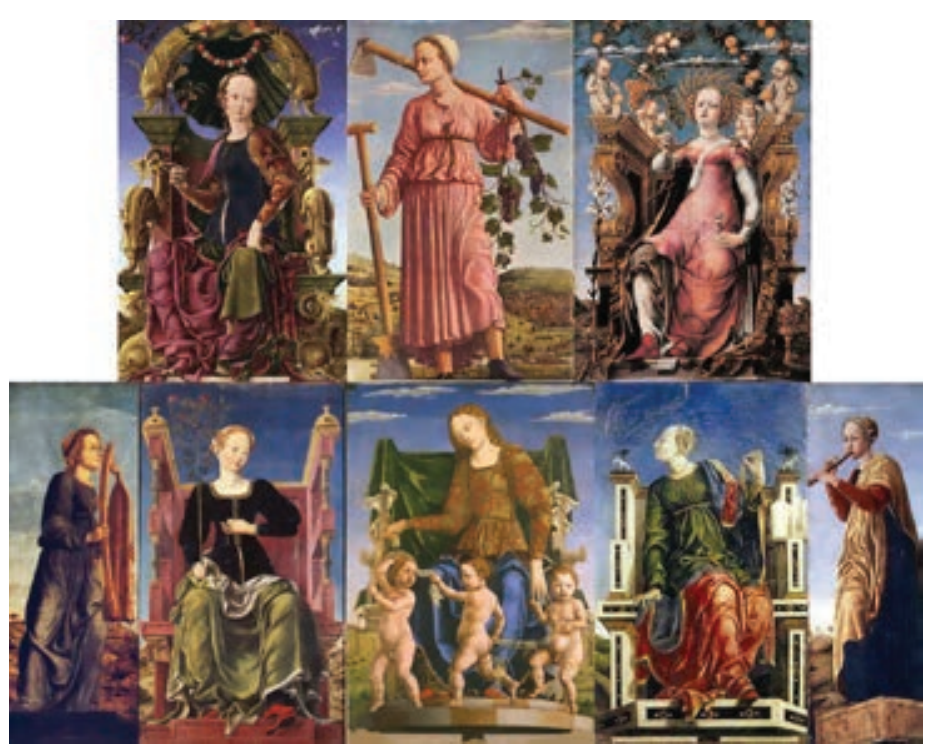

Илл. 133. Музы из студиоло дворца Бельфьоре. 1447 - до 1463 г. Верхний ряд: Каллиопа. Козимо Тура (Национальная галерея, Лондон); Полигимния. Неизвестный художник (Картинная галерея, Берлин); Талия. Микеле Паннонио (Музей изобразительных искусств, Будапешт).

Нижний ряд: Мельпомена. Неизвестный художник (Музей изобразительных искусств, Будапешт); Эрато. Анджело Макканьино (Национальная пинакотека, Феррара); Терпсихора. Анджело Макканьино и Козимо Тура (Музей Польди Пеццоли, Милан); Урания. Неизвестный художник (Национальная пинакотека, Феррара); Эвтерпа. Неизвестный художник (Музей изобразительных искусств, Будапешт)

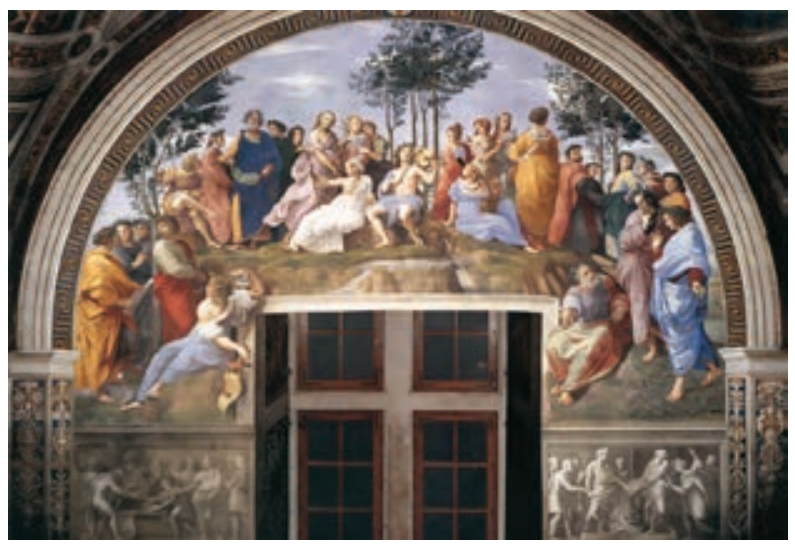

Илл. 134. Рафаэль Санти.

Парнас. 1509-1510.

Ватиканские музеи, Ватикан

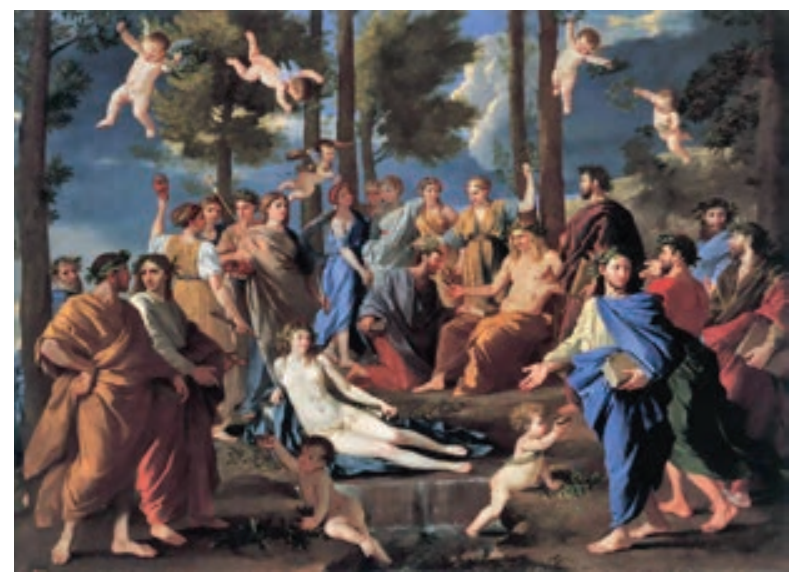

Илл. 135. Никола Пуссен. Парнас. 1630-1631. Прадо, Мадрид 